Keywords: ionising radiation; adverse effect; in utero exposure; haematological malignancy; leukaemia; lymphoma; cohort study; Russian Federation

\title{
In utero exposure to radiation and haematological malignancies: pooled analysis of Southern Urals cohorts
}

\author{
Joachim Schüz ${ }^{*}{ }^{1}$, Isabelle Deltour ${ }^{1}$, Lyudmila Y Krestinina ${ }^{2}$, Yulia V Tsareva $^{3}$, Evgenia I Tolstykh ${ }^{2}$, \\ Mikhail E Sokolnikov ${ }^{3}$ and Alexander V Akleyev ${ }^{2,4}$ \\ ${ }^{1}$ International Agency for Research on Cancer (IARC), Section of Environment and Radiation, Lyon, France; ${ }^{2}$ Urals Research Center \\ for Radiation Medicine, Chelyabinsk, Russian Federation; ${ }^{3}$ Southern Urals Biophysics Institute, Ozyorsk, Russian Federation and \\ ${ }^{4}$ Chelyabinsk State University, Chelyabinsk, Russian Federation
}

Background: It is scientifically uncertain whether in utero exposure to low-dose ionising radiation increases the lifetime risk of haematological malignancies.

Methods: We pooled two cohorts from the Southern Urals comprising offspring of female workers of a large nuclear facility (the Mayak Production Association) and of women living in areas along the Techa River contaminated by nuclear accidents/waste from the same facility, with detailed dosimetry.

Results: The combined cohort totalled 19536 subjects with 700504 person-years at risk over the period of incidence follow-up, and slightly more over the period of mortality follow-up, yielding 58 incident cases and 36 deaths up to age 61 years. Risk was increased in subjects who received in utero doses of $\geqslant 80 \mathrm{mGy}$ (excess relative risk (ERR): $1.27 ; 95 \%$ confidence interval (CI): -0.20 to 4.71), and the risk increased consistently per $100 \mathrm{mGy}$ of continuous exposure in utero (ERR: 0.77 ; $\mathrm{Cl}$ : 0.02 to 2.56 ). No association was apparent in mortality-based analyses. Results for leukaemia and lymphoma were similar. A very weak positive association was observed between incidence and postnatal exposure.

Conclusions: In summary, the results suggest a positive association between in utero exposure to ionising radiation and risk of haematological malignancies, but the small number of outcomes and inconsistent incidence and mortality findings preclude firm conclusions.

Ionising radiation and radioactive nuclides have long been established as carcinogens, associated with an increased risk of many cancers, including most haematological malignancies (International Agency for Research on Cancer (IARC), 2012). However, scientific uncertainty remains as to the magnitude of risk related to protracted low-dose exposure and various time windows of exposure (Kesminiene and Schüz, 2014). Data on cancer risks associated with in utero exposure are particularly sparse, providing inconclusive evidence, especially regarding adult-onset cancers (Doll and Wakeford, 1997; Boice and Miller, 1999; Streffer et al, 2003; International Agency for Research on Cancer (IARC), 2012). Few studies have provided informative data because of the long follow-up time required. Follow-up of the atomic bomb survivors in Japan revealed an excess risk of solid cancers in survivors exposed in utero (Preston et al, 2008), but there were too few haematological malignancies for a dose-response analysis (Delongchamp et al, 1997). The Oxford Survey of Childhood Cancers found an increased risk of childhood cancer associated with obstetric radiography, and particularly radiography during the first trimester (Stewart and Kneale, 1970; Bithell and Stewart, 1975), as well as other earlier studies (McMahon, 1962; Harvey et al, 1985). No associations between childhood haematological malignancies and maternal occupational exposures have been reported in the offspring of a cohort of US radiologic technologists

*Correspondence: Dr J Schüz; E-mail: schuzj@iarc.fr 
or in a nested case-control study of offspring of UK radiation workers (Johnson et al, 2008; Bunch et al, 2009). Several casecontrol studies of children with leukaemia and lymphoma have investigated maternal diagnostic radiation exposure during pregnancy, with inconsistent results, although one large case-control study in the United Kingdom, which used medical records to assess exposure, showed a small statistically non-significant increase in the risk of leukaemia and lymphoma (Rajaraman et al, 2011). Overall, the evidence from studies on childhood cancers after in utero exposure to ionising radiation suggests a non-zero increase in risk at doses as low as $10 \mathrm{mSv}$ (Wakeford and Little, 2002, 2003; Schulze-Rath et al, 2008).

Two additional sizable cohorts of subjects exposed in utero originate from the operation of a large nuclear facility in the Southern Urals (Russian Federation) called the Mayak Production Association that was established in 1948 and was part of the former Soviet nuclear weapons programme (Akleyev et al, 1995). The facility houses several nuclear reactors, a radiochemical plant, and a plutonium-producing reactor. Two sources of exposure are associated with the facility. First, because of a lack of adequate radioprotection in the early days of operation, the workforce was exposed to considerable doses of external radiation. Depending on the worksite, there was also a risk of inhalation of plutonium aerosols. Therefore, the offspring of female Mayak workers may have received high doses in utero (Vasilenko et al, 2007; Vostrotin et al, 2014). Second, because of discharge of nuclear waste into the surrounding environment in the 1950s (particularly into the nearby Techa River) and a major nuclear accident in 1957, when a chemical explosion of a storage tank released as much as 100 tons of highlevel radioactive waste, the offspring of women living along the Techa River or areas affected by the fallout during this time period were also exposed to substantial doses in utero (Degteva et al, 2006, 2012; Maynard et al, 2015a,b). The offspring of women exposed to each of these sources were identified and two cohorts established, with the oldest cohort members now in their early 60s. The two cohorts have been analysed separately for both incidence and mortality of haematological malignancies. Based on 32 incident cases, analysis of the Mayak female worker offspring cohort (MWOC) has revealed some weak indications of increased risk (Deltour et al, 2016), whereas analysis based on 26 incident cases in the Techa River in utero exposed cohort (TRCIU) has not shown an increase (Kharyuzov et al, 2015).

The objective of this study was to pool the data from these two cohorts to increase the statistical power of analyses to investigate the association between in utero exposure to ionising radiation and the risk of incidence and mortality of haematological malignancies.

\section{MATERIALS AND METHODS}

Study population. The TRCIU comprised all individuals born alive between January 1950 and September 1961 to mothers who have been permanent residents in the villages along the Techa River (41 villages) before and/or during their pregnancy between January 1950 and December 1960. The MWOC comprised all individuals born alive in the town of Ozyorsk between January 1948 and December 1988 to mothers who were members of the Mayak worker cohort that comprised workers employed by the Mayak Production Association (a large nuclear facility) for any period of time between January 1948 and December 1982 at one of the nuclear reactors, the plutonium production plant, the radiochemical plant, the water treatment plant, or the mechanical repair plant (Deltour et al, 2016). Because of the differences in inclusion criteria between the two cohorts, many members of the MWOC had an estimated zero radiation dose despite the potential of in utero exposure, whereas the TRCIU by definition comprised only individuals who had a non-zero dose (with few exceptions). There was no overlap of subjects between MWOC and TRCIU.

Data collection. The TRCIU members were followed up for incidence of haematological malignancies for as long as they lived within the Chelyabinsk oblast (administrative region) or the Kurgan oblast from January 1953 to December 2009. Until 2005, paper copies of information on cancer diagnoses were obtained from the Chelyabinsk and Kurgan oblast oncology dispensaries and from the clinical department of the Urals Research Center for Radiation Medicine (URCRM). From 2005 onwards, electronic information was obtained from the cancer registries of the oblasts. Mortality was followed up from January 1950 to December 2009, within the same catchment area as for the incidence analysis. This follow-up was conducted using records from the URCRM causeof-death registry covering the entire time period (Winkelmann et al, 2002; Startsev et al, 2015). Subjects were followed up for incidence and mortality until their death, their emigration out of the catchment area, or the end of the follow-up period, or - for incidence analysis only - until their first cancer diagnosis. Until 2006, cohort members' residency and vital status were followed up through queries to the Chelyabinsk and Kurgan oblast address bureaus and civil registration offices. In 2006, the Russian legislation on data confidentiality changed, and informed consent became required for follow-up. As a result, a new follow-up procedure was established that relied on (1) searches in existing lists of Techa residents covered by free medical services and in the Ozyorsk database, (2) phone interviews with residents of the city of Chelyabinsk, (3) surveys mailed to relatives of cohort members, (4) interviews with cohort members visiting the URCRM clinic or receiving examinations by the URCRM mobile medical team, and (5) interviews with cohort members' relatives during such visits.

The MWOC members were followed up from January 1948 until December 2009, or until their death, their emigration out of the town of Ozyorsk, their loss to follow-up for another reason, or - for incidence analysis only - their first cancer diagnosis, whichever occurred first. The Epidemiology Laboratory at the Southern Urals Biophysics Institute established its own active follow-up process, with cause of death data obtained from the Ozyorsk cause-of-death registry and cross-checked against information from any other sources available, such as medical records, autopsy protocols, histological examination protocols, and communications with relatives (Azizova et al, 2012). The most reliable information available was then recorded in the database, with autopsy protocols considered to be the most reliable sources and communications with relatives the least reliable. The Southern Urals Biophysics Institute now maintains its own cancer registry of all incident cases occurring in cohort members, based on information obtained from local hospital records. Until 2006, vital status was followed up through queries to the local address bureau and civil registration office, and from then on with the requirement of obtaining informed consent before accessing these sources.

Information was anonymised before analysis. The study was approved by the Ethics committee of the URCRM, Chelyabinsk, Russia, and by the Ethics committee of the Southern Urals Biophysics Institute (SUBI), Ozyorsk, Russia.

Exposure assessment. To study the risk of haematological malignancies and the associated mortality, the estimated dose to red bone marrow was calculated for each member of the combined cohort.

For TRCIU members, in utero and annual postnatal doses were estimated using the Techa River Dosimetry System 2009 (Degteva et al, 2006) that includes a special algorithm for in utero dose estimations. Red bone marrow doses were calculated using a common protocol based on external dose rates in residential areas and village-average intake functions, then individualised according to age and history of residence in either the Techa River settlements or the East Urals Radioactive Trace (the area contaminated by 
fallout from the nuclear accident). Accumulated fetal doses of strontium-89, strontium-90, and cesium-137 were assumed to be the sources of internal in utero exposure. Fetal biokinetic and dosimetric models for strontium adapted for the Techa River population were used for the calculation (Maynard et al, 2015a,b; Shagina et al, 2015a). The model published in the International Commission on Radiological Protection's Publication 88 was used to calculate the in utero doses from cesium (International Commission on Radiological Protection (ICRP), 2001). Estimates of dietary intake of strontium90 and cesium-137 among adult Techa River residents (Tolstykh et al, 2011, 2013), adjusted for increased food consumption by pregnant women (Shagina et al, 2015a), were also used. External in utero exposure during pregnancy was estimated using the Techa River Dosimetry System 2009, using maternal uterine exposure as a surrogate measure. Postnatal exposure was estimated using the same system for individuals who continued to live in the contaminated areas or who were evacuated (as exposure because of bone-seeking strontium-90 continued long after intake regardless of place of residence). Breast milk, another source of radionuclides for infants, was also taken into account (Shagina et al, 2015b). Strontium-89 and strontium-90 exposure accounts for $\sim 90 \%$ of the total red bone marrow dose.

For MWOC members, fetal exposure to external radiation was estimated using the Mayak Worker Dosimetry System 2008 that incorporates estimates of each mother's annual uterine dose of $\gamma$-radiation based on film badge records and work history (Schonfeld et al, 2012). Pregnancies were assumed to have begun 280 days before childbirth. The period of no occupational exposure (because of maternity leave, other leave days, and the practice of transferring pregnant workers to worksites with no ionising radiation exposure) was assumed to be a total of 175 days for women who gave birth before 1960, and 265 days thereafter, as described elsewhere (Schonfeld et al, 2012). Dose rates were adjusted as appropriate for pregnancies that occurred very close together. The mothers of MWOC members may also have been exposed to plutonium; exposure to internal radiation was modelled for the MWOC-specific analysis but not used in the pooled analysis (Deltour et al, 2016). For MWOC members who later became Mayak workers themselves (and therefore members of the Mayak worker cohort), estimates of postnatal occupational exposure to $\gamma$-radiation (red bone marrow dose) were extracted from the Mayak Worker Dosimetry System 2008.

Statistical analysis. We used Poisson regression methods to quantify excess relative risk (ERR) and relative risk (RR) as functions of red bone marrow dose received in utero $\left(d_{\mathrm{iu}}\right)$ and postnatally $\left(d_{\mathrm{pn}}\right)$ for both incidence and mortality of haematological malignancies. The person-years table was stratified by population (Slavs, Tatars, and Bashkirs (part of the TRCIU) and Ozyorsk residents (part of the MWOC)), sex, 5-year age group, and birth period (before 1955, 1955-1959, 1960-1969, 1970-1979, and $1980-1988)$, as well as by in utero and postnatal dose $(<1,1-4$, $5-9,10-19$, and further $10 \mathrm{mGy}$ intervals up to the maximum dose) lagged by 1 year until age 15 years and by 2 years thereafter. Analyses were based on linear ERR models of the form $\lambda_{0}(a, s, p, r)\left(1+\beta d_{\mathrm{iu}}+\delta d_{\mathrm{pn}}\right)$ and on log-linear RR models of the form $\lambda_{0}(a, s, p, r) \exp \left(\beta d_{\mathrm{iu}}+\delta d_{\mathrm{pn}}\right)$, where $\lambda_{0}()$ is the baseline hazard rate function, modelled as a function of $\log \left(\right.$ age/45), $\log ^{2}$ (age/45) $(a)$, sex $(s)$, birth period (before 1955, 1955-1959, or after 1959) $(p)$, and place of residence $(r)$. Hypothesis tests and $95 \%$ confidence intervals (CIs) were based on likelihood ratio tests and direct evaluation of the profile likelihood.

Within the combined cohort, ERR and RR were calculated for all haematological malignancies combined (defined by diagnostic codes 200-208 in the International Classification of Diseases, 9th Revision) and for leukaemia (codes 204-208) and lymphoma (codes 200-202) separately (all subtypes combined). Additional analyses were conducted to investigate the risk of haematological malignancies occurring during childhood (i.e., before age 15 years).

\section{RESULTS}

The combined cohort totalled 19536 subjects with 700504 personyears at risk over the period of incidence follow-up, and slightly more (19956 subjects with 706269 person-years at risk) over the period of mortality follow-up (Tables $1 \mathrm{~A}$ and B). In both individual cohorts, approximately half of the members were known to be alive and cancer free at the end of follow-up. The mean age of those alive and under follow-up was 51 years at the end of the follow-up (median age 52.3 years, maximum age 61 years); $32.4 \%$ were below and $67.6 \%$ above 50 years of age. The rate of loss to follow-up was somewhat higher in the MWOC. The proportion of deaths was somewhat higher in the TRCIU, and this was as expected because of this cohort's earlier average date of birth. The most frequent causes of deaths were injury and poisoning (29\%), followed by circulatory system diseases (15\%).

A total of 58 individuals were diagnosed with a haematological malignancy in the combined cohort: 28 with leukaemia, 28 with lymphoma, and 2 with multiple myeloma (Table 2). An equal number of males and females were affected, and 13 subjects were diagnosed before age 15 years. The numbers of individuals diagnosed were $7(12.1 \%)$ in the $0-9$-year-old age group, $9(15.5 \%)$ in the 10-19-year-old group, $12(20.7 \%)$ in the $20-29$ year-old group, 6 (10.3\%) in the 30-39-year-old group, 15 (25.9\%) in the 40-49-year-old group, and $9(15.5 \%)$ above age 50 years. There were no cases of chronic lymphoid leukaemia. The numbers of deaths were substantially smaller (totalling 36 in the combined cohort), with more deaths related to leukaemia than to lymphoma.

The maximum in utero dose received was $1.05 \mathrm{~Gy}$, but most subjects ( $>55 \%$ ) received doses of $<2 \mathrm{mGy}$ (Table 3 ). The in utero dose distributions in the MWOC and the TRCIU were similar, with both cohorts contributing equally to the lower and higher dose ranges. Nearly half $(48.5 \%)$ of the combined cohort (with 339539 person-years at risk) had received postnatal ionising radiation doses of $<1 \mathrm{mGy}$, but $24.5 \%$ of the cohort (with 174124 person-years at risk) had received accumulated doses of $\geqslant 20 \mathrm{mGy}$. The main difference between the two cohorts was that there was no correlation between in utero and postnatal doses in the MWOC (Pearson's correlation coefficient: 0.02), whereas there was some correlation in the TRCIU (Pearson's correlation coefficient: 0.46 ); this finding was expected because postnatal dose in the MWOC comes from occupational exposure, whereas place of residence is the major determinant of dose in the TRCIU.

Table 4 shows the risk analyses of the combined cohorts for incidence and mortality of all haematological malignancies combined, modelled as ERR and RR as described in the Statistical Analysis section. With regard to incidence, categorical analyses showed considerable effect estimates in the two highest dose categories of in utero exposure, but only small increases with increasing postnatal dose. Analyses of continuous exposure showed some risk increase per $100 \mathrm{mGy}$ of in utero dose, but no association between risk and postnatal dose. For mortality, the weak associations observed with incidence were further attenuated; no association was apparent with either in utero or postnatal exposure.

The results of separate analyses of leukaemia and lymphoma cases were similar to the overall results (Table 5). Although the ERRs of both lymphoma and leukaemia increased slightly per $100 \mathrm{mGy}$ of exposure, this difference was only statistically significant for leukaemia. There was evidence of an association between in utero dose and incidence, but not mortality.

Restricting the analysis to outcomes occurring before the subjects reached the age of 15 years (to evaluate the risk of 
Table 1A. Incidence of haematological malignancies; demographic characteristics and outcomes of the study population of the two Southern Urals cohorts - the Techa River in utero exposed cohort (TRCIU) and the Mayak female worker offspring cohort (MWOC) - exposed to ionising radiation in utero

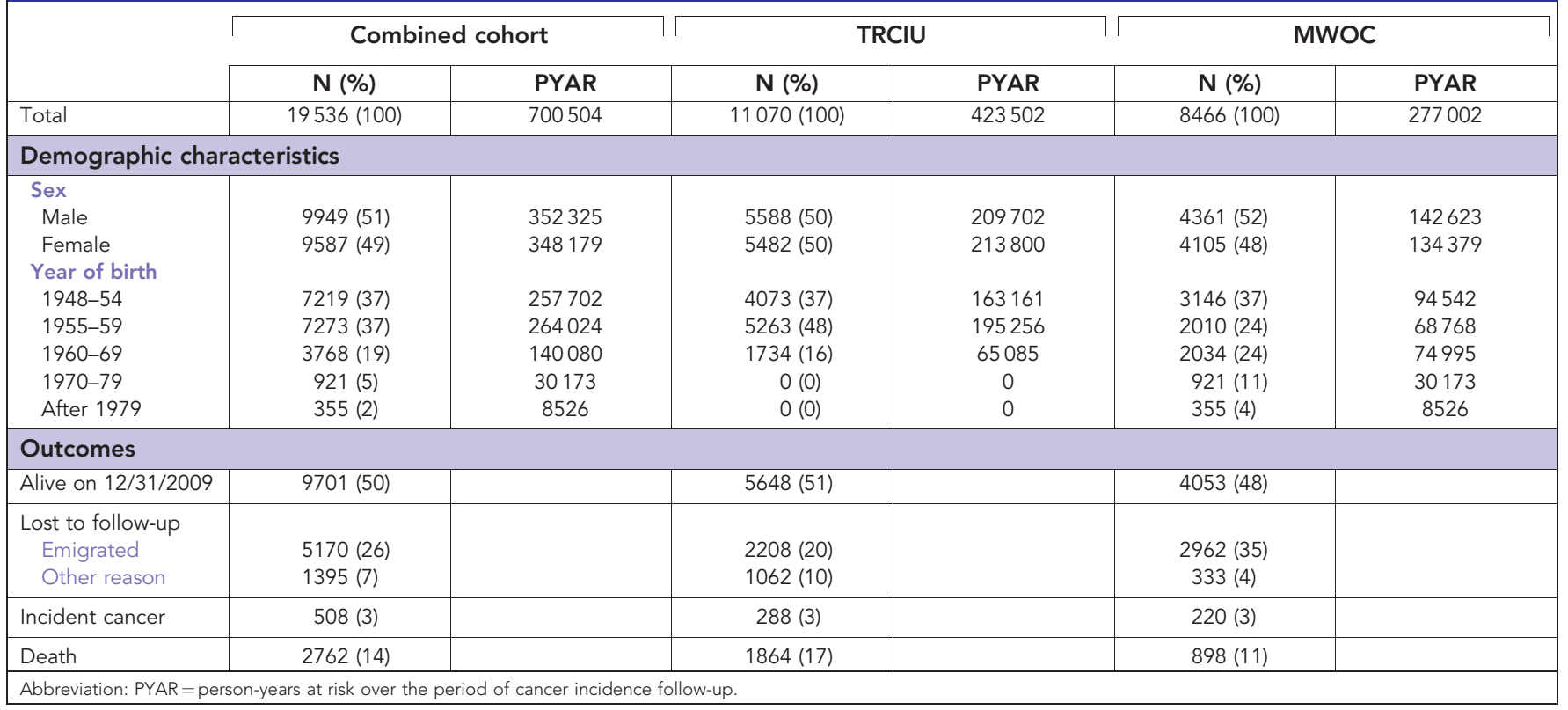

Table 1B. Mortality of haematological malignancies; demographic characteristics and outcomes of the study population of the two Southern Urals cohorts - the Techa River in utero exposed cohort (TRCIU) and the Mayak female worker offspring cohort (MWOC) - exposed to ionising radiation in utero

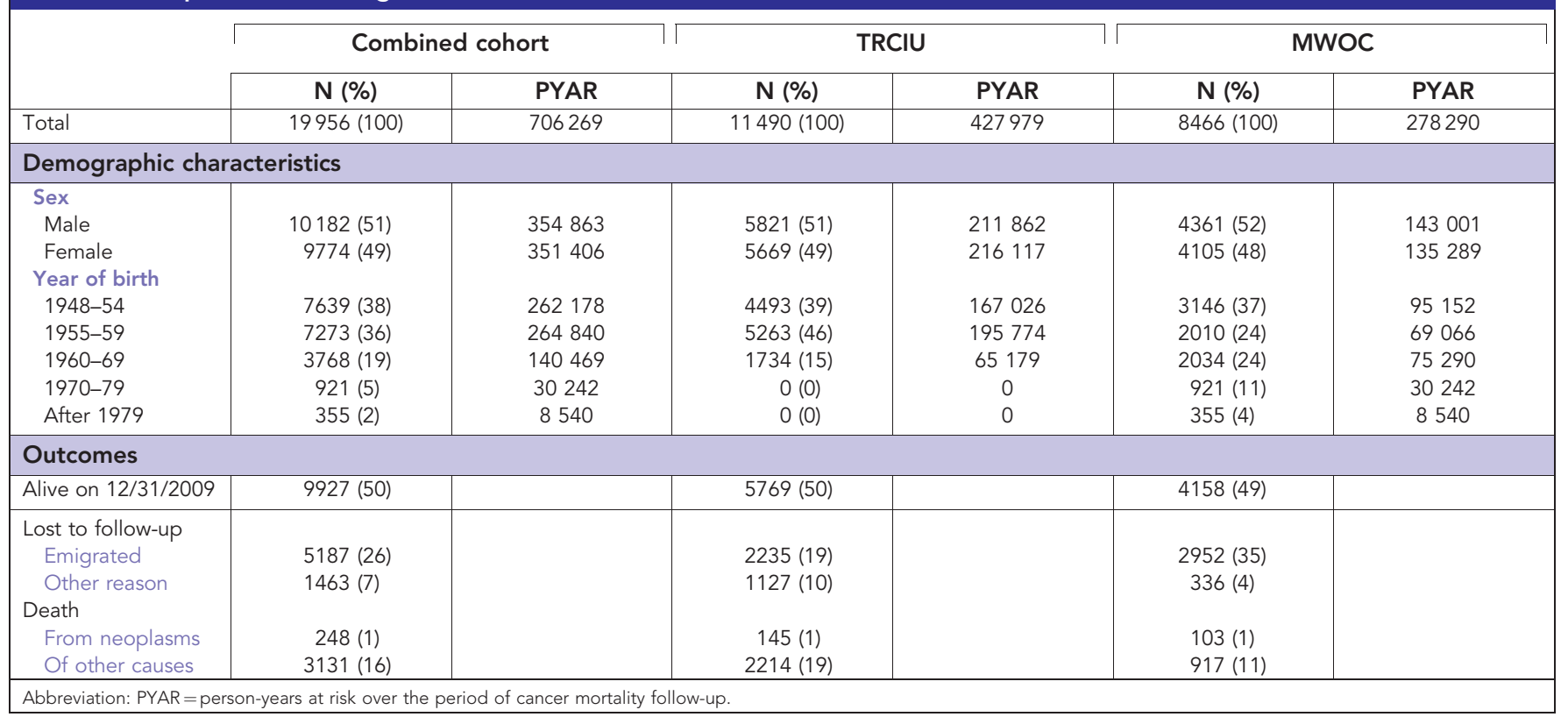

developing a haematological malignancy specifically during childhood) reduced the number of incident cases to 13 (of which 9 were diagnosed with leukaemia), resulting in an ERR per $100 \mathrm{mGy}$ of -0.09 (95\% CI: (lower bound not defined) to 1.74) and an RR per $100 \mathrm{mGy}$ of 0.78 (95\% CI: 0.20 to 1.54 ) for in utero exposure (not shown in tables).

\section{DISCUSSION}

In this large study pooling data from two Southern Urals cohorts exposed in utero to ionising radiation, with a total of $>700000$ person-years at risk, we observed 58 incident cases of haematological malignancies. Excess risk was increased by 77\% (CI: 2 to $257 \%)$ per $100 \mathrm{mGy}$ in utero dose. Some cohort members also had postnatal exposure to ionising radiation that was correlated with in utero exposure in one of the two cohorts, but adjustment for postnatal exposure did not alter the observed effect of in utero exposure. A total of 36 deaths from haematological malignancies occurred in the combined cohort, but mortality was not correlated with in utero exposure. For both incidence and mortality, the results were similar between leukaemia and lymphoma, and none of the incident cases of leukaemia were chronic lymphoid leukaemia. There is no straightforward explanation for the 
Table 2. Incidence and mortality of haematological malignancies in the two Southern Urals cohorts - the Techa River in utero exposed cohort (TRCIU) and the Mayak female worker offspring cohort (MWOC) - exposed to ionising radiation in utero

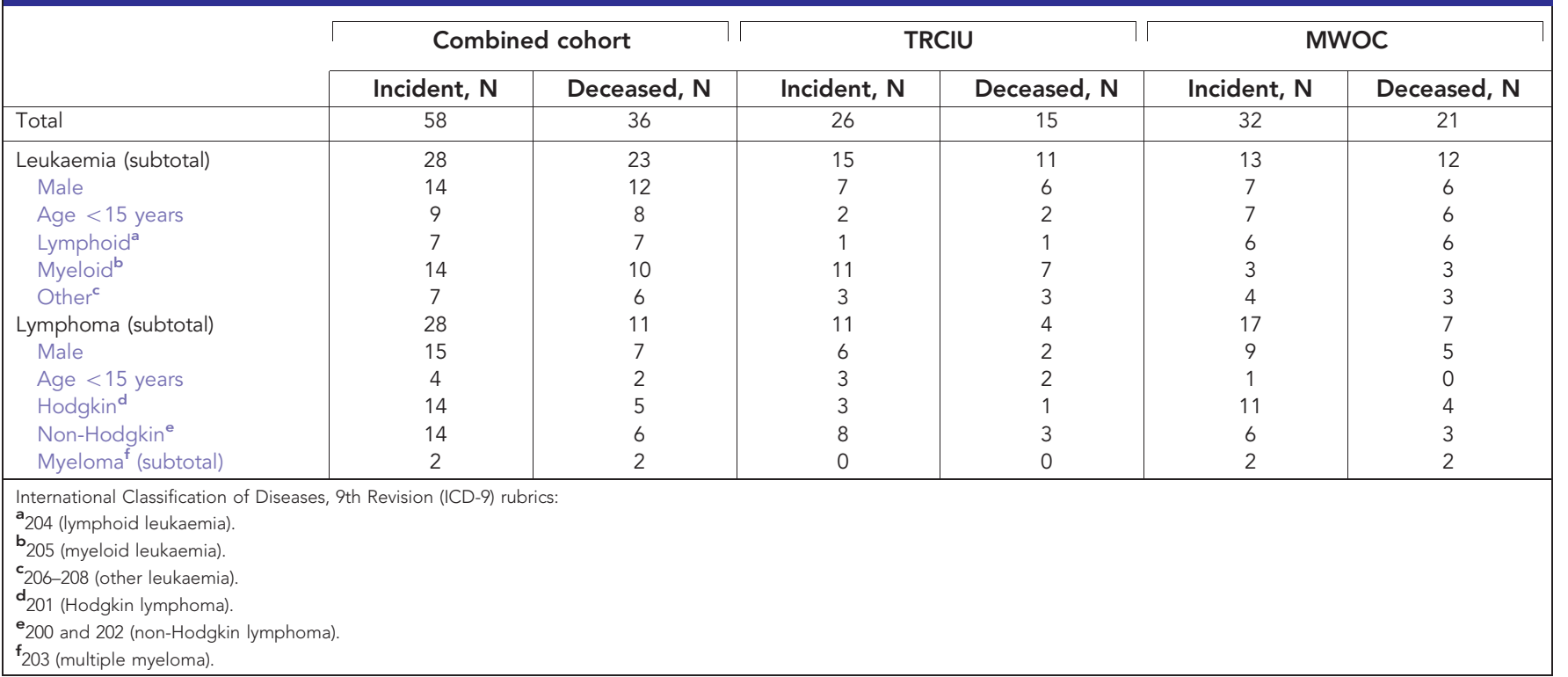

Table 3. Distribution of in utero red bone marrow doses (in Gy) within the two Southern Urals cohorts - from external radiation in the Mayak female worker offspring cohort (MWOC) and from external and internal radiation in the Techa River in utero exposed cohort (TRCIU) - followed up for incident cases of all haematological malignancies (International Classification of Diseases, 9th Revision (ICD-9) rubrics 200-208)

\begin{tabular}{|c|c|c|c|c|c|c|}
\hline \multirow[b]{2}{*}{ Dose percentile (Gy) } & \multicolumn{2}{|c|}{ Combined cohort } & \multicolumn{2}{|c|}{ TRCIU } & \multicolumn{2}{|c|}{ MWOC } \\
\hline & $\begin{array}{c}\text { No malignancy } \\
(\mathrm{N}=19478)\end{array}$ & $\begin{array}{c}\text { Malignancy } \\
(\mathrm{N}=58)\end{array}$ & $\begin{array}{l}\text { No malignancy } \\
(\mathrm{N}=11044)\end{array}$ & $\begin{array}{c}\text { Malignancy } \\
(\mathrm{N}=26)\end{array}$ & $\begin{array}{l}\text { No malignancy } \\
(\mathrm{N}=8434)\end{array}$ & $\begin{array}{l}\text { Malignancy } \\
(\mathrm{N}=32)\end{array}$ \\
\hline 50th (median dose) & 0.001 & 0.002 & 0.002 & 0.003 & 0.000 & 0.000 \\
\hline 75th & 0.012 & 0.032 & 0.013 & 0.015 & 0.010 & 0.045 \\
\hline 90th & 0.076 & 0.159 & 0.079 & 0.203 & 0.072 & 0.153 \\
\hline 95th & 0.147 & 0.228 & 0.156 & 0.219 & 0.142 & 0.496 \\
\hline Maximum dose & 1.053 & 0.534 & 1.053 & 0.228 & 0.945 & 0.534 \\
\hline
\end{tabular}

differences seen for incidence and mortality, as it was observed for all diagnostic subtypes; all of the 36 deaths were also among the 58 observed incidence cases. Hence, chance, with smaller numbers for mortality, is the most likely reason, especially with 9 incident compared with 3 deceased cases in the highest exposure category of $\geqslant 80 \mathrm{mGy}$. No associations were found between exposure and childhood haematological malignancies (i.e., those diagnosed before age 15 years), but the number of cases was small.

Overall, the available evidence suggests that there is a non-zero increase in the risk of childhood cancer (including leukaemia and lymphoma) associated with in utero exposure to ionising radiation doses of $\geqslant 10 \mathrm{mSv}$ (Wakeford and Little, 2002, 2003). However, there remains doubt as to whether this constitutes a causal association (Tubiana et al, 2009), given that there have been largescale studies on diagnostic radiation in utero that showed no association (Shu et al, 2002). We observed no association between risk and exposures to doses of $<20 \mathrm{mGy}$, and a borderline statistically significant association with $100 \mathrm{mGy}$ increases in exposure from log-linear models in the incidence follow-up. Virtually no data are available on lifetime cancer risk after in utero exposure, with too-small numbers in the in utero exposed cohort of the atomic bomb survivors in Japan (Delongchamp et al, 1997).
Experimental animal studies and mechanistic data suggest that the fetus and embryo are indeed radiosensitive and that radiationrelated effects, even those related to low doses, such as bystander effects and genomic instability, have detrimental effects on fetal development (Streffer, 2004). However, it is possible that the increase in cancer risk due to in utero exposure may be less than that due to postnatal early-life exposure, if defence mechanisms exist to destroy malignant cells during prenatal development (Pampfer and Streffer, 1989; Nakano et al, 2014).

Cohort studies have also been conducted on the populations exposed as adults in the same settings as our two in utero exposed cohorts. A study in the Techa River exposed population showed an excess risk of 0.22 per $100 \mathrm{mGy}$ for leukaemia other than chronic lymphoid leukaemia, but no other haematological malignancies (Krestinina et al, 2013). A study in the Mayak workers showed an increased leukaemia mortality risk of $\sim 7$ per gray of exposure in the 3-5 years before death, and 0.45 per gray of exposure in the 5-45 years before death, but no association with plutonium exposure (Shilnikova et al, 2003). We did not find an association with postnatal exposure, but the numbers of postnatally exposed cohort members were small, especially at higher dose ranges. Follow-up of our cohorts but restricted to individuals born in 
Table 4. Excess relative risk (ERR) and relative risk (RR) of incidence and mortality of haematological malignancies related to in utero, postnatal, and continuous exposure to ionising radiation within the combined Southern Urals cohort

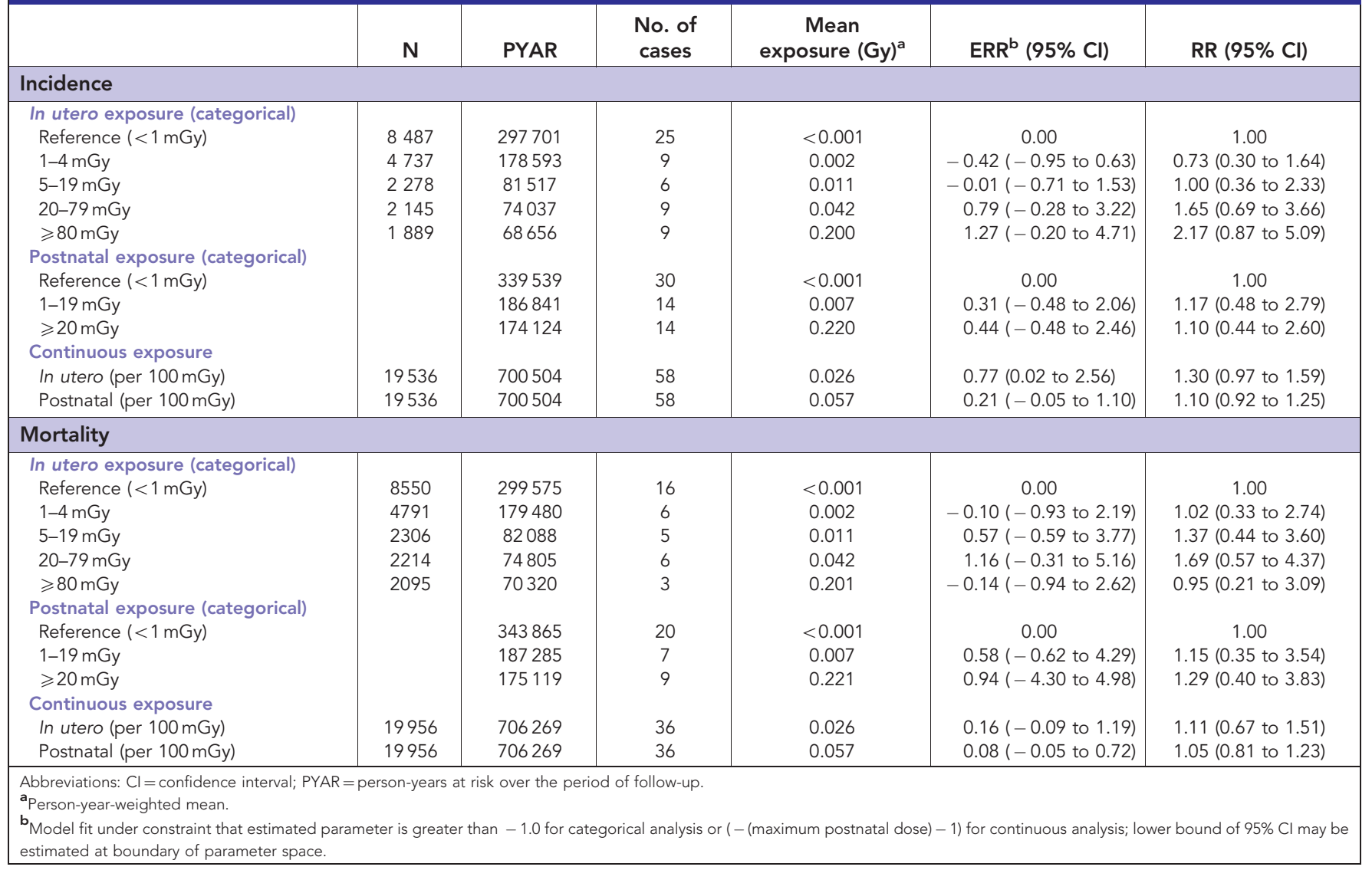

Table 5. Excess relative risk (ERR) and relative risk (RR) of incidence and mortality of leukaemia and of lymphoma related to in utero and postnatal exposure to ionising radiation within the combined Southern Urals cohort

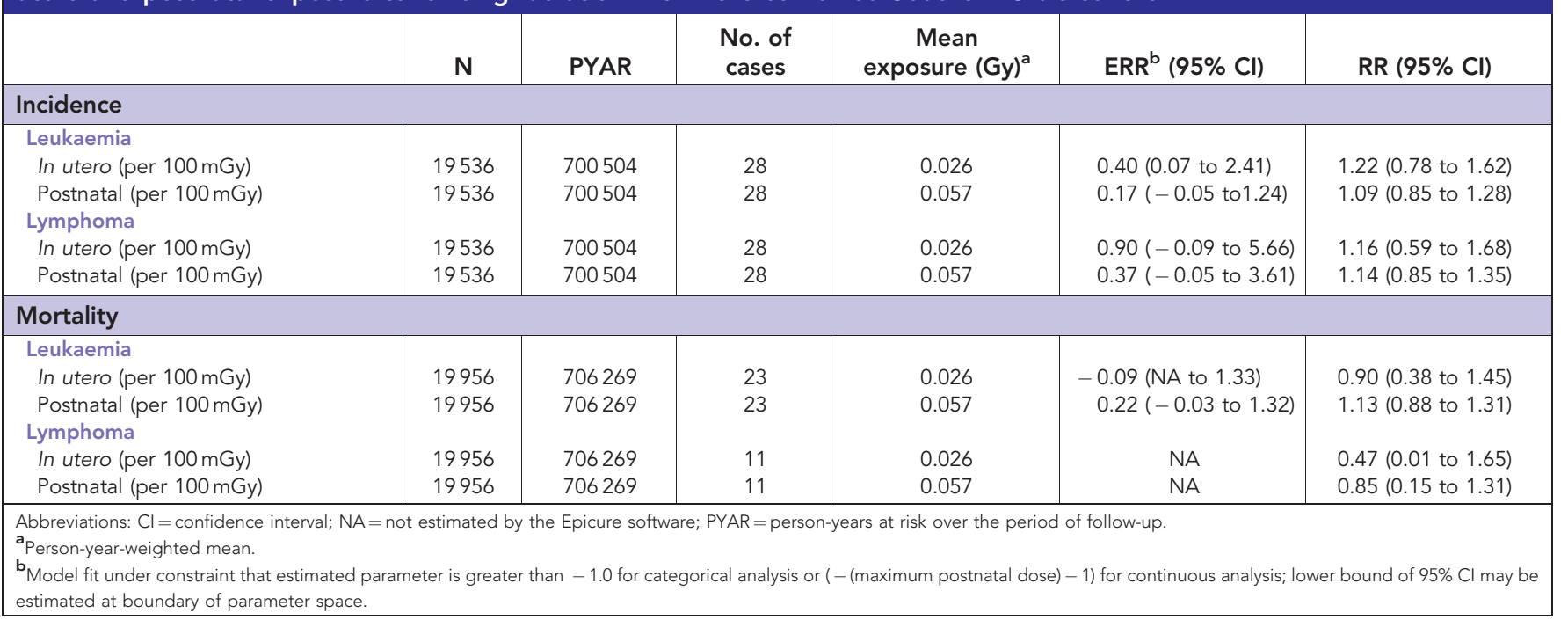

1950-1961 for solid cancers showed no association with in utero exposure but with postnatal exposure to ionising radiation (Akleyev et al, 2016).

The strengths of this study include the sizable cohort, the relatively long follow-up period, and the extensive work previously done on dosimetry that was adapted and put to use in the present study. In addition, the fact that some cohort members received relatively high doses in utero (especially during the earlier years) enabled investigation of risk across a wide exposure range in an otherwise locally restricted and relatively homogeneous population. Overall, because of this unique study setting, the Southern Urals combined cohort is exceptionally informative in addressing the lifelong cancer risk resulting from in utero exposure to ionising radiation, both on its own and through comparisons with the atomic 
bomb survivors (a smaller cohort), medical exposure cohorts (a different type of exposure), and cohorts related to the Chernobyl accident (exposures that occurred at a date 30-40 years later).

The study's main limitation is the small number of cancers observed because of the relatively young age of the cohort, but this will change over the coming decade as many members reach their 70s. The small number observed thus far precludes firm conclusions at this point. That $26 \%$ of cohort subjects migrated out of the catchment area over the up to 60 years of follow-up period and were censored at their date of migration might be a concern, but as it is unlikely that moving away was associated with the level of in utero exposure it results rather in a loss of statistical power of the study than introducing any bias. Uncertainty in dose estimation is an inherent limitation when reconstructing exposures occurring several decades in the past, and the dosimetry developed in large-scale projects using dosimetry data for the evaluation of the external and internal doses include numerous radionuclide measurements in Techa riverside residents and measurements of $\gamma$-radiation fields in residential areas and on Techa riverbanks, and is considered the best data available. Another limitation is the strong correlation between in utero exposure and postnatal exposure in one of the two cohorts and the fact that preconceptional exposure of the parental gonads was not considered. The lack of information on exposure from radioactive iodine is assumed to be a minor issue in evaluating the risk of haematological malignancies, but an assessment of iodine-131 doses among Techa River cohort members has shown that individual thyroid doses can reach several grays, especially in individuals born in 1948-1950, the period of maximal airborne releases from the Mayak Production Association (Eslinger et al, 2014; Napier et al, 2015). This suggests that future research on thyroid cancer may be of interest. A model for estimating plutonium exposure among the female Mayak workers was developed for the purpose of the present study, but because this exposure was found to have no impact on the MWOC results and there was no plutonium exposure in the TRCIU, plutonium exposure was not included in the pooled analyses. Overall, we had no information on other potential confounding factors, but while natural radiation (because of the defined relatively small geographical area where the mothers lived during pregnancy) and smoking (being a modest risk factor for only myeloid leukaemia (Vineis et al, 2004)) are unlikely to have an impact, the lack of information on postnatal medical radiation is a limitation, although it is rather speculative of whether it may be correlated with in utero exposure.

Doses are lower compared with early studies of offspring of mothers who underwent diagnostic X-ray procedures, possibly explaining why we did not see the same association with childhood cancer; the majority of cases in our study however are adults for which there are little data in the literature. The in utero exposure in the atomic bomb survivor cohort was on average slightly higher ( 14\% with exposures $\geqslant 0.1 \mathrm{~Gy}$; Preston et al, 2008) but, as said, risk of haematological malignancies was not analysed because of small numbers.

\section{CONCLUSION}

Our results suggest a positive association between in utero exposure to ionising radiation and risk of haematological malignancies, but the small number of observed cases, inconsistent incidence and mortality findings, and limited follow-up preclude firm conclusions. Half of the combined cohort was still alive at the end of 2009 and the oldest members had only reached age 61 years; a further 10 years of follow-up would increase the number of cases to the extent that higher statistical power and more robust results would be obtained. The lack of opportunities to address this research question in other settings makes this unique cohort extremely valuable for future research.

\section{ACKNOWLEDGEMENTS}

This work was supported by the European Atomic Energy Community's Seventh Framework Programme ([FP7/2007-2013] [FP7/2007-2011]) under Grant Agreement Number 249675, as part of the SOLO (Epidemiological Studies of Exposed Populations in the Southern Urals) project. We thank Dr Vadim Vostrotin for his support in establishing dosimetry in the MWOC and Dr Sergey Romanov for his leadership of the MWOC-related project work. We also thank Dr Dale Preston for statistical advice and consultation on the use of Epicure software, Dr Graham Byrnes for statistical advice, and Dr Christian Streffer for comments on the discussion of potential mechanisms. We are grateful to Dr John Harrison, Dr Richard Haylock, and Ms Svetlana Carr for their skillful coordination of the SOLO project.

\section{CONFLICT OF INTEREST}

The authors declare no conflict of interest.

\section{REFERENCES}

Akleyev A, Deltour I, Krestinina L, Sokolnikov M, Tsareva Y, Tolstykh E, Schüz J (2016) Incidence and mortality of solid cancers in people exposed in utero to ionizing radiation: pooled analyses of two cohorts from the Southern Urals, Russia. PLoS One 11(8): e0160372.

Akleyev AV, Kossenko MM, Silkina LA, Degteva MO, Yachmenyov VA, Awa A, Akiyama M, Veremeyeva GA, Vozilova AV, Kyozumi S (1995) Health effects of radiation incidents in the southern Urals. Stem Cells 13(Suppl 1): 58-68.

Azizova TV, Fedirko V, Tsareva Y, Tretyakov F, Lassen CF, Friis S, Schüz J (2012) Mayak workers study cohort. An inter-institutional comparison of causes of death in the cause-of-death register of Ozyorsk in the Russian Federation. Methods Inf Med 51(2): 144-149.

Bithell JF, Stewart AM (1975) Pre-natal irradiation and childhood malignancy: a review of British data from the Oxford Survey. Br J Cancer 31(3): 271-287.

Boice Jr JD, Miller RW (1999) Childhood and adult cancer after intrauterine exposure to ionizing radiation. Teratology 59(4): 227-233.

Bunch KJ, Muirhead CR, Draper GJ, Hunter N, Kendall GM, O’Hagan JA, Phillipson MA, Vincent TJ, Zhang W (2009) Cancer in the offspring of female radiation workers: a record linkage study. $\mathrm{Br}$ J Cancer 100(1): 213-218.

Degteva MO, Shagina NB, Vorobiova MI, Anspaugh LR, Napier BA (2012) Reevaluation of waterborne releases of radioactive materials from the Mayak Production Association into the Techa River in 1949-1951. Health Phys 102(1): 25-38.

Degteva MO, Vorobiova MI, Tolstykh EI, Shagina NB, Shishkina EA, Anspaugh LR, Napier BA, Bougrov NG, Shved VA, Tokareva EE (2006) Development of an improved dose reconstruction system for the Techa River population affected by the operation of the Mayak Production Association. Radiat Res 166(1 Pt 2): 255-270.

Delongchamp RR, Mabuchi K, Yoshimoto Y, Preston DL (1997) Cancer mortality among atomic bomb survivors exposed in utero or as young children, October 1950-May 1992. Radiat Res 147(3): 385-395.

Deltour I, Tsareva Y, Schonfeld SJ et al. (2016) Risk of haematological malignancies in the offspring of female workers of the Mayak nuclear facility in the Southern Urals, Russian Federation. Radiat Res 186(4): 415-421.

Doll R, Wakeford R (1997) Risk of childhood cancer from fetal irradiation. Br J Radiol 70: 130-139.

Eslinger PW, Napier BA, Anspaugh LR (2014) Representative doses to members of the public from atmospheric releases of (131)I at the Mayak Production Association facilities from 1948 through 1972. J Environ Radioact 135: 44-53.

Harvey EB, Boice Jr JD, Honeyman M, Flannery JT (1985) Prenatal x-ray exposure and childhood cancer in twins. $N$ Engl J Med 312: 541-545. 
International Agency for Research on Cancer (IARC) (2012) Radiation. IARC Monogr Eval Carcinog Risks Hum 100D: 1-437.

International Commission on Radiological Protection (ICRP) (2001) Doses to the embryo and fetus from intakes of radionuclides by the mother. ICRP Publication 88. Ann ICRP 31: 1-3.

Johnson KJ, Alexander BH, Doody MM, Sigurdson AJ, Linet MS, Spector LG, Hoffbeck W, Simon SL, Weinstock RM, Ross JA (2008) Childhood cancer in the offspring born in 1921-1984 to US radiologic technologists. Br J Cancer 99(3): 545-550.

Kesminiene A, Schüz J (2014) Radiation: ionizing, ultraviolet, and electromagnetic. In: World Cancer Report 2014, Stewart BW, Wild CP (eds). pp 143-150. International Agency for Research on Cancer (IARC): Lyon, France.

Kharyuzov YY, Krestinina LY, Tostykh EI, Akleyev AV (2015) Methodology of the follow-up and analysis of cancer incidence and mortality in persons exposed in utero due to anthropogenic contamination of the Techa River. Radiat Risk 24: 92-114 (in Russian).

Krestinina LY, Davis FG, Schonfeld S, Preston DL, Degteva M, Epifanova S, Akleyev AV (2013) Leukaemia incidence in the Techa River Cohort: 19532007. Br J Cancer 109(11): 2886-2893.

Maynard MR, Shagina NB, Tolstykh EI, Degteva MO, Fell TP, Bolch WE (2015a) Fetal organ dosimetry for the Techa River and Ozyorsk offspring cohorts, part 1: a Urals-based series of fetal computational phantoms. Radiat Environ Biophys 54(1): 37-46.

Maynard MR, Shagina NB, Tolstykh EI, Degteva MO, Fell TP, Bolch WE (2015b) Fetal organ dosimetry for the Techa River and Ozyorsk Offspring Cohorts, part 2: radionuclide $S$ values for fetal self-dose and maternal cross-dose. Radiat Environ Biophys 54(1): 47-59.

MacMahon B (1962) Prenatal x-ray exposure and childhood cancer. J Natl Cancer Inst 28: 1173-1191.

Nakano M, Nishimura M, Hamasaki K, Mishima S, Yoshida M, Nakata A, Shimada Y, Noda A, Nakamura N, Kodama Y (2014) Fetal irradiation of rats induces persistent translocations in mammary epithelial cells similar to the level after adult irradiation, but not in hematolymphoid cells. Radiat Res 181(2): 172-176.

Napier BA, Eslinger PW, Tolstykh EI, Vorobiova MI, Tokareva EE, Akhramenko BN, Krivoschapov VA, Degteva MO (2015) Calculation of individual doses for the TRC members exposed to atmospheric radioiodine from the Mayak releases. Milestone 10/12, US-Russian Joint Coordinating Committee on Radiation Effects Research. Project 1.1. Chelyabinsk and Richland, Washington. (in Russian and English).

Pampfer S, Streffer C (1989) Increased chromosome aberration levels in cells from mouse fetuses after zygote X-irradiation. Int J Radiat Biol 55(1): 85-92.

Preston DL, Cullings H, Suyama A, Funamoto S, Nishi N, Soda M, Mabuchi K, Kodama K, Kasagi F, Shore RE (2008) Solid cancer incidence in atomic bomb survivors exposed in utero or as young children. J Natl Cancer Inst 100(6): 428-436.

Rajaraman P, Simpson J, Neta G, Berrington de Gonzalez A, Ansell P, Linet MS, Ron E, Roman E (2011) Early life exposure to diagnostic radiation and ultrasound scans and risk of childhood cancer: case-control study. BMJ 342: $\mathrm{d} 472$.

Schonfeld SJ, Tsareva YV, Preston DL, Okatenko PV, Gilbert ES, Ron E, Sokolnikov ME, Koshurnikova NA (2012) Cancer mortality following in utero exposure among offspring of female Mayak Worker Cohort members. Radiat Res 178(3): 160-165.

Schulze-Rath R, Hammer GP, Blettner M (2008) Are pre- or postnatal diagnostic X-rays a risk factor for childhood cancer? A systematic review. Radiat Environ Biophys 47(3): 301-312.

Shagina NB, Fell TP, Tolstykh EI, Harrison JD, Degteva MO (2015a) Strontium biokinetic model for the pregnant woman and fetus: Application to Techa River studies. J Radiol Prot 35: 659-676.

Shagina NB, Tolstykh EI, Fell TP, Smith T, Harrison JD, Degteva MO (2015b) Strontium biokinetic model for the lactating woman and transfer to breast milk: application to Techa River studies. J Radiol Prot 35: 677-694.
Shilnikova NS, Preston DL, Ron E, Gilbert ES, Vassilenko EK, Romanov SA, Kuznetsova IS, Sokolnikov ME, Okatenko PV, Kreslov VV,

Koshurnikova NA (2003) Cancer mortality risk among workers at the Mayak nuclear complex. Radiat Res 159(6): 787-798.

Shu XO, Potter JD, Linet MS, Severson RK, Han D, Kersey JH, Neglia JP, Trigg ME, Robison LL (2002) Diagnostic X-rays and ultrasound exposure and risk of childhood acute lymphoblastic leukemia by immunophenotype. Cancer Epidemiol Biomarkers Prev 11(2): 177-185.

Startsev N, Dimov P, Grosche B, Tretyakov F, Schüz J, Akleyev A (2015) Methods for ensuring high quality of coding of cause of death. The mortality register to follow Southern Urals populations exposed to radiation (published online ahead of print March 2015). Methods Inf Med 54: 359-363.

Stewart A, Kneale GW (1970) Radiation dose effects in relation to obstetric x-rays and childhood cancers. Lancet 1(7658): 1185-1188.

Streffer C, Shore R, Konermann G, Meadows A, Uma Devi P, Preston Withers J, Holm LE, Stather J, Mabuchi K, HR. (2003) Biological effects after prenatal irradiation (embryo and fetus). A report of the International Commission on Radiological Protection. Ann ICRP 33(1-2): 5-206.

Streffer C (2004) Bystander effects, adaptive response and genomic instability induced by prenatal irradiation. Mutat Res 568(1): 79-87.

Tolstykh EI, Degteva MO, Peremyslova LM, Shagina NB, Shishkina EA, Krivoshchapov VA, Anspaugh LR, Napier BA (2011) Reconstruction of long-lived radionuclide intakes for Techa riverside residents: strontium90. Health Phys 101(1): 28-47.

Tolstykh EI, Degteva MO, Peremyslova LM, Shagina NB, Vorobiova MI, Anspaugh LR, Napier BA (2013) Reconstruction of long-lived radionuclide intakes for Techa riverside residents: 137Cs. Health Phys 104(5): 481-498.

Tubiana M, Feinendegen LE, Yang C, Kaminski JM (2009) The linear nothreshold relationship is inconsistent with radiation biologic and experimental data. Radiology 251(1): 13-22.

Vasilenko EK, Khokhryakov VF, Miller SC, Fix JJ, Eckerman K, Choe DO, Gorelov M, Khokhryakov VV, Knyasev V, Krahenbuhl MP, Scherpelz RI, Smetanin M, Suslova K, Vostrotin V (2007) Mayak worker dosimetry study: an overview. Health Phys 93(3): 190-206.

Vineis P, Alavanja M, Buffler P, Fontham E, Franceschi S, Gao YT, Gupta PC, Hackshaw A, Matos E, Samet J, Sitas F, Smith J, Stayner L, Straif K, Thun MJ, Wichmann HE, Wu AH, Zaridze D, Peto R, Doll R (2004) Tobacco and cancer: recent epidemiological evidence. J Natl Cancer Inst 96(2): 99-106.

Vostrotin VV, Fell TP, Smith TJ, Romanov SA (2014) Retrospective estimation of Plutonium-239 doses from transfer to the fetus for Mayak PA workers. Int J Radiat Biol 90(11): 1036-1042.

Wakeford R, Little MP (2002) Childhood cancer after low-level intrauterine exposure to radiation. J Radiol Prot 22(3A): A123-A127.

Wakeford R, Little MP (2003) Risk coefficients for childhood cancer after intrauterine irradiation: a review. Int J Radiat Biol 79(5): 293-309.

Winkelmann RA, Tretyakov FD, Startsev NV, Kolyado IB, Gusev BI, Grosche B, Storm HH, Hall P (2002) Cause-of-death registers in radiationcontaminated areas of the Russian Federation and Kazakhstan. Radiat Environ Biophys 41(1): 5-11.

(c) (1) (2) (2) This work is licensed under the Creative Commons Coy Attribution-Non-Commercial-Share Alike 4.0 International License. To view a copy of this license, visit http:// creativecommons.org/licenses/by-nc-sa/4.0/

(C) The Author(s) named above 2017 